Mariana Bonano *

Universidad Nacional de Tucumán - CONICET, Argentina
El hilo de la fábula Universidad Nacional del Litoral, Argentina ISSN-e: 2362-5651

Periodicidad semestral, julio-diciembre, 2021 vol. 19, núm. 22, e0009, revistaelhilodelafabula@ fhuc.unl.edu.ar

Recepción: 02082021 Aprobación: 08112021

URL: http://portal. amelica.org/ameli/ jatsRepo/247/2472702006/ index.html DOI: https://doi. org/10.14409/hf.19.22. e0009

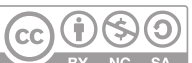

Esta obra está bajo una Licencia Creative Commons Atribución-NoComercialCompartirlgual 4.0 Internacional.

\section{Más allá de Walsh. Textualidades de no ficción en perfiles biográficos de cronistas latinoamericanas de comienzos del siglo XXI}

\author{
Beyond Walsh. Non-fiction textualities in biographic profiles \\ of Latin American female chroniclers from beginnings of the \\ 21st century
}

\begin{abstract}
Resumen
Como se sabe, las transformaciones del relato realista decimonónico y los cuestionamientos a esta estética por parte de autores y críticos del siglo XX, han puesto en entredicho la idea de escritura como representación mimética de lo real. En el menoscabo del verosímil realista no solo cumplieron un papel relevante las vanguardias históricas, sino muchas de las formas narrativas agrupadas, a falta de una nominación más precisa, bajo el término «no ficción» (novelas documentales, biografías, autobiografías, testimonios, entre otras). Es en esta línea que entronca la escritura del argentino Rodolfo Walsh, autor de obras de investigación que plasman no tanto una voluntad de representación de lo real cuanto de intervención en lo real al denunciar crímenes de Estado silenciados. En los libros de Walsh, el trabajo de no ficción queda evidenciado mediante la selección, el montaje y la narrativización operados sobre el material testimonial (Amar Sánchez). Esta forma de intervención walshiana puede ser puesta en diálogo con algunos de los rasgos presentes en los y las cronistas del Cono Sur, situados/as en los albores del siglo XXI: la mirada crítica hacia la sociedad y la adopción de una voz propia por parte del periodista; el interés por los sujetos marginales del sistema; el despliegue de una actitud experimental en la escritura; la búsqueda de un público; el postulado de ejercicio periodístico como intervención política. A la luz de las proposiciones arriba especificadas, el presente trabajo aspira a examinar en paralelo dos obras biográficas de cronistas mujeres latinoamericanas: Opus Gelber. Retrato de un pianista (2019), de Leila Guerriero, y La hermana menor (2018), de Mariana Enriquez. El diálogo entre ambos perfiles que esta indagación establecerá tiene por fin aportar a la labor de delimitación de las formas de intervención sobre lo real por parte de autoras actuales del periodismo narrativo.
\end{abstract}

\section{Palabras clave}

periodismo narrativo, reapropiaciones de la crónica, no ficción latinoamericana, narradoras actuales, perfiles biográficos.

\footnotetext{
* Mariana Bonano es doctora en Letras por la Universidad Nacional de Tucumán, donde se desempeña como Profesora Adjunta Regular en Periodismo y Seminario de Trabajo Final de la carrera de Ciencias de la Comunicación. Investigadora Adjunta del CONICET-INVELEC (Instituto de Investigaciones sobre el Lenguaje y la Cultura). Ha difundido numerosos artículos sobre literatura y crítica literaria en compilaciones y revistas especializadas. En la actualidad, aborda en particular la escritura de mujeres cronistas, con especial atención a las cuestiones de la intimidad y de las autofiguraciones.
} 


\begin{abstract}
As it is well known, the transformations of the nineteenth-century realistic narrative and the questioning of this aesthetic by twentieth-century authors and critics have called into question the idea of writing as a mimetic representation of reality. In detracting from the plausible realist, not only the historical avant-garde played a relevant role, but also many of the narrative forms grouped, in the absence of a more precise name, under the term «non-fiction» (documentary novels, biographies, autobiographies, testimonies, among others). It is in this line that the writing of the Argentine Rodolfo Walsh, author of research works that embody not so much a will to represent the real as to produce an intervention in the real by denouncing silenced State crimes. In Walsh's books, the non-fiction work is evidenced by the selection, montage and narrativization operated on the testimonial material (Amar Sánchez). This form of Walshian intervention can be put into dialogue with some of the features present in the chroniclers of the Southern Cone, situated at the dawn of the twenty-first century: the critical look towards society and the journalist's adoption of a voice of its own; the interest in the marginal subjects of the system; the display of an experimental attitude in writing; the search for an audience; the postulate of journalistic exercise as a political intervention. This paper aims to examine two biographical works of Latin American female chroniclers in parallel: Opus Gelber. Retrato de un pianista (2019), by Leila Guerriero, and La hermana menor (2018), by Mariana Enriquez. The purpose of the dialogue between the two profiles is to contribute to the delimitation of the forms of intervention on reality by current authors of narrative journalism.
\end{abstract}

\title{
Keywords
}

narrative Journalism, reappropriations of the chronicle, latin American non fiction, current women narrators, biographical profiles.

La pregunta por parte de un amplio sector de la crítica literaria y cultural acerca de las formas de aproximación a lo real en narradores y narradoras actuales no se limita solo a las obras más estrictamente identificadas con la ficción, sino que atañe también a las «escrituras referenciales», aquellas que como las biografías y las autobiografías se presentan en tanto «discursos en los que existe una información histórica», una información que «parte precisamente de una presunción de semejanza o analogía con algún segmento de lo real» (Catelli, 2007:293). En relación con el discurso de la autobiografía, Nora Catelli advierte a partir de los aportes de Philippe Lejeune que en este espacio no se juega con la verosimilitud ni con el efecto de lo real sino con la imagen misma de lo real. A partir de lo planteado por la autora, advertimos empero que no solo el espacio de lo estrictamente autobiográfico puede ser pensado de este modo; la relación conflictiva entre la escritura y la representación de/o la aproximación a lo real se manifiesta también en un espectro diverso de textos pasibles de ser identificados con el universo amplio de la narrativa 
de no ficción (novelas documentales, biografías, autobiografías, diarios de viaje, crónicas, testimonios, entre otros). Es justamente esta serie textual la que en las últimas décadas manifiesta, según advierte Mónica Bernabé, «un notorio impulso hacia el realismo» (2006:8). Y, agrega la autora, reinscribe el intento de narrar desde la tensión entre ficción y realidad que impulsó en su momento a la novela decimonónica. Se trata de «narrativas urgidas por relatar y transferir algo de lo real en esforzada batalla contra la opacidad irreductible del lenguaje» (Bernabé, 2006:8).

En América Latina, la no ficción conforma un horizonte discursivo que entronca con la crónica de los escritores modernistas de finales del siglo XIX y comienzos del $\mathrm{XX}^{1} \mathrm{y}$, más adelante, con la obra de una figura singular en el campo de la narrativa argentina sesentista: Rodolfo Walsh y sus textos de investigación periodística Operación masacre (1957), Quién mató a Rosendo (1969) y El caso Satanowsky (1973). En particular, el primero mencionado da cuenta de una modalidad narrativa donde, según advierte Ana María Amar Sánchez (1992), el trabajo de no ficción queda evidenciado mediante la selección, montaje y narrativización operado sobre el material testimonial. Frente a la objetividad aparente y lo que Walsh considera como la «verdad mentirosa» de la prensa oficialista, el despliegue de una escritura de no ficción permite al investigador-periodista asumir tanto su propia subjetividad como la verdad de los sucesos que relata en función de un afán autoral de denuncia de un crimen político. La no ficción que Walsh despliega a lo largo de las páginas de Operación masacre no redunda en un relato lineal; la historia se arma mediante la exposición de datos y acontecimientos que a la manera de un rompecabezas, exige al lector la labor de puesta en orden y encastre de las diferentes piezas que conforman la trama. Las dudas que el propio narrador expresa acerca de aspectos puntuales de la crónica, no atentan contra el valor que adquieren los documentos y testimonios en tanto evidencias de investigación puestos al servicio de la reconstrucción lo más exacta posible y verosímil de los hechos. Walsh ejercita así en Operación masacre una práctica narrativa fuertemente documentada y al mismo tiempo impulsa, frente a la no ficción desplegada por otros periodistas de investigación, una escritura innovadora que incumbe también un planteo gnoseológico alejado del de la tradición de la actividad periodística pretendidamente objetiva y mimética. La reivindicación de la subjetividad en la escritura atañe en su caso a una postura ética que le permite cuestionar los efectos desmovilizadores de la prensa informativa sobre el público. En el Prólogo a la primera edición en libro de Operación masacre, el autor afirma: «Escribí este libro para que fuese publicado, para que actuara, no para que se incorporase al vasto número de las ensoñaciones de ideólogos» (Walsh, 1998:255).²

Las huellas de la no ficción impulsada por los cronistas modernistas latinoamericanos y el propio Rodolfo Walsh particularmente en Argentina, ${ }^{3}$ prevalecen en la escritura de autores y autoras actuales cuyas prácticas se inscriben dentro de la tendencia que la crítica identifica como «periodismo de autor» (Bernabé, 2010; Gorodischer, 2018), esto es, aquella que enfatiza la aproximación del cronista al presente social a partir de una mirada personal y de una subjetividad que permite a ese actor resignificar la realidad narrada. ${ }^{4}$ Siguiendo el camino trazado por Walsh, muchos de los y las cronistas actuales erigen en sus prácticas una mirada crítica sobre la sociedad coetánea, al tiempo que exponen sus propias vacilaciones en el relato que componen. ${ }^{5}$ Según señalamos en un trabajo previo destinado a las direcciones de la no ficción y el periodismo narrativo en los albores del siglo XXI (Bonano, 2014), dichos cronistas presentan sin embargo una inflexión en relación con la concepción de la escritura como acción política implicada en la labor de Walsh. La salida de la redacción en pos de la exploración de los márgenes (urbanos, sociales) es uno de los movimientos que se reiteran en las producciones de los narradores y narradoras contemporáneos/as. A diferencia de Walsh, tal acción no reviste necesariamente una intencionalidad marcadamente política. La visibilización de las minorías en tanto «otredad» a la que en forma recurrente apuntan los textos, se realiza a través de un recorrido en el que más que «desentrañar una verdad», se establecen relaciones orientadas, en palabras de Bernabé, «a organizar imágenes, perspectivas y afec- 
tos» (2010:9). El afán totalizador retrocede para dar lugar a la fragmentación y dispersión propias del recorrido aleatorio del paseante citadino, identificado este último con el cronista que participa con su cuerpo en el suceso que narra (Bonano, 2014). El narrador o la narradora se adentra en la realidad con el propósito de cuestionarla, al complejizar las diversas facetas que aquella entraña.

De lo expuesto más arriba puede deducirse que las formas de intervención sobre lo real en los y las cronistas de finales del siglo XX y comienzos del XXI se expresan en una pluralidad de registros y modulaciones complejas y diversas susceptibles de ser identificadas con historias de no ficción. ${ }^{6}$ En Argentina, Leila Guerriero (Junín, Buenos Aires, 1967) y Mariana Enriquez (Buenos Aires, 1973) son dos de las figuras prominentes de este movimiento de escritores y escritoras que se aproximan a lo real a partir de la adopción de una voz propia y cuyo discurso fluctúa entre las esferas de la narrativa literaria y el relato periodístico. Sin embargo, ambas representan posiciones disímiles, a nuestro entender, dentro del campo cultural. Enriquez tiene una trayectoria periodística primero como freelance y ligada luego al diario argentino Página/12, a cuyo staff se incorporó en 1997 como subeditora del Suplemento Radar. Respecto del ámbito literario, publicó novelas y dos colecciones de cuentos vinculados con el género del terror; 7 el 30 de mayo de 2020 ocupó el cargo de Directora de Letras del Fondo Nacional de las Artes, en el que se desempeña hasta la actualidad. En el caso de Guerriero, su rol como periodista aparece más asociado en cambio a su participación como colaboradora de diversos suplementos y revistas culturales y de periodismo narrativo de circulación digital, pertenecientes tanto al ámbito hispanoamericano como también europeo, ${ }^{8}$ del mismo modo que su escritura de libros de no ficción, en los que despliega historias de largo aliento y de intenso tiempo de investigación. En su rol de editora, Guerriero ha publicado antologías de crónicas y ha dirigido colecciones editoriales dedicadas a la no ficción. A diferencia de Enriquez, no publicó narrativa de ficción.

A la luz del panorama de la no ficción y sus formas de intervención en lo real planteado en párrafos anteriores, nos proponemos poner en relación dos textos de la autoría de Enriquez y Guerriero, respectivamente, focalizando un aspecto poco estudiado en relación con estas autoras: la escritura de perfiles entendidos como biografías extensas sobre personalidades célebres. Se apunta en particular a la indagación en la obra de Guerriero publicada en mayo de 2019 y dedicada a perfilar al reconocido músico argentino de proyección internacional, Bruno Gelber. La aproximación a Opus Gelber. Retrato de un pianista, tiene el propósito de profundizar en el examen de una zona de la obra de Guerriero a nuestros ojos fundamental para el conocimiento de la crónica latinoamericana actual: la apelación al perfil en tanto discurso donde la narración si bien está presente, se ancla fuertemente a la entrevista, instituye un diálogo que viabiliza la construcción identitaria del «otro». ${ }^{9}$ En diálogo con el libro de Guerriero, examinaremos el retrato sobre la escritora Silvina Ocampo realizado por Enriquez en La hermana menor y publicado por primera vez en 2014 por la editorial de la Universidad Diego Portales, de Chile, cuya dirección está curiosamente a cargo de la propia Guerriero. Es a ella en su rol de editora a quien Enriquez agradece al final de su libro: «Gracias primero y especialmente a Leila Guerriero, editora exigente y atentísima, siempre preocupada y encantadora. Las virtudes que pueda tener este libro son responsabilidad de ella, los defectos todos míos» (Enriquez, 2018:s/p). ${ }^{10}$

Lo primero a señalar es que Guerriero es una escritora de perfiles y, por añadidura, la autora se percibe a sí misma como tal. ${ }^{11}$ En efecto, Opus Gelber no es el primero ni el único perfil en el que la autora trabaja, pero sí el de mayor alcance tanto por el trabajo de campo que le demanda como por la extensión que adquiere el texto. Producto de reiterados encuentros con Gelber a lo largo de todo un año, el texto de 333 páginas que Guerriero elabora, da cuenta de aquello que aparece como central en las definiciones sobre el género ofrecidas por la autora:

Un perfil es, por definición, la mirada de otro. Y esa mirada es, siempre, subjetiva. Donde subjetiva no quiere decir artera, donde subjetiva no quiere decir vil, donde subjetiva no quiere decir miserable. Donde subjetiva quiere decir la mirada de una persona que cuenta lo que ve o lo que, honestamente, cree ver (Guerriero, 2008). 
Dicha posición es el punto de partida que permite a la cronista acercarse a una eximia y compleja figura como la de Gelber, cuya imagen pública parece entrar en contradicción con la imagen del personaje ofrecida por la narradora en el libro, la que apunta sobre todo a situar a esa figura en el contexto de su mundo privado y de su cotidianeidad. En tanto retratista biógrafa, Guerriero practica lo que podemos llamar «periodismo de inmersión», esto es, siguiendo a María Angulo Egea (s/f), aquel que involucra un trabajo de «exhaustivo reporterismo y/o documentación (con un proceso de inmersión significativo para abordar un tema, asunto, territorio o personaje con rigor y profundidad), que muestra la capacidad interpretativa de un autor que articula su relato narrativamente» (17). La labor de reporterismo de Guerriero queda asentada en el texto sobre Gelber que construye; la narración de la cantidad de veces que acude a una cita pedida por ella o bien, convocada por el propio músico no es un dato anecdótico en el relato, como tampoco el detalle de los múltiples traslados que realiza a diferentes puntos de Buenos Aires con el fin de obtener un testimonio por parte de algún familiar o amigo de Gelber, o la enumeración de las llamadas telefónicas a Gelber que no obtienen respuestas. La cronista no solo relata estos hechos a primera vista menores, sino que enfatiza en ellos; construye un núcleo de sentido orientado a mostrar las dificultades y los obstáculos con los que lidió en su intento por acceder a la intimidad del personaje. Aunque Gelber se muestra abierto a la charla y establece una relación cordial con la entrevistadora - mantiene con ella un trato parecido al que entablaría con una amiga - , la narración da cuenta de una imposibilidad para aproximarse a su espacio íntimo - pensamos «lo íntimo» a partir de Nora Catelli (2007), en los términos de una penetración del sujeto sobre sí mismo o sobre otro, a la vez que una penetración de algo en un sujeto, o de un sujeto en otro ${ }^{[12]}$ - . La cronista insiste, reitera, en diferentes segmentos de su obra perfil, acerca de ese escollo:

En el vagón del subte solo pienso en él. En que quizás nunca pueda saber cómo es cuando está solo.

Quizás todo fue un largo camino para llegar a dos, a tres, a cuatro frases en las que está él. No todo lo que repite - la palabra vacía- sino él: él.

«Hacé lo que te parezca. Me podés preguntar absolutamente cualquier cosa.»

Por momentos parecerá verdad. (Guerriero, 2019:113) $)^{13}$

En todas las entrevistas habla de la polio - sin tapujos - , del Edipo con su madre - sin tapujos-, de lo cruel que era Scaramuzza - sin tapujos - , desplegando una intimidad que cobra visos de revelación entre entrevistadores o personas del público a quienes logra convencer que no ha contado nada de todo eso antes. Si su arte consiste en ser el mejor vehículo de la obra de otros, él es su mayor composición. Y nadie puede interpretarla. $(135)^{14}$

Mediante intromisiones como las del párrafo antes citado, el yo narrativo asoma en la superficie textual; la «mirada» constitutiva de esa figura de autora/cronista en su relación con el otro instituye un modo de diálogo; interpela al «otro» para ayudarlo a construir una imagen de sí mismo, en un movimiento similar al del ensayo literario estudiado por Alberto Giordano (1991). ${ }^{15}$ A pesar de la opacidad con que se presenta el sujeto identitario del personaje Gelber para la retratista, esta insiste en la demanda de apertura de la interioridad del yo perfilado, y en esa dialéctica entablada en el intercambio de la palabra entre ambos, afloran algunos núcleos de sentido que no admiten, sin embargo, definiciones simples ni conclusivas. El discurso de la crónica perfil construido se aleja de la retórica de la objetividad periodística para poner en cuestión todo, aun el testimonio de Gelber en relación con algunos de los aspectos más caros a su intimidad: aquellos relacionados con la novela familiar, el cuerpo, la enfermedad. ${ }^{16}$ Las dudas y las vacilaciones de la narradora emergen incluso respecto de episodios insondables en la vida del artista. Acerca de la muerte de la madre de Gelber, aduce: «Las circunstancias dependen de quién las relate» (100). Y es esta misma ambigüedad la que impulsa a la cronista a continuar indagando en esa identidad indecidible; la estimula al punto de sentirse no solo atraída por el protagonista de su historia, sino seducida por esa personalidad caprichosa, capaz de envolver a los demás en su confusa telaraña: 
Un espejo pulido para reflejar más perfectamente. Ni siquiera he podido confirmar que esa frase sea de Leonardo da Vinci.

Sin tener idea de hacia dónde voy, avanzo.

Pronto estaré en su telaraña (84).

No está en juego aquí, como sí ocurre en Walsh, el testimonio en tanto prueba de una verdad de los hechos que se apunta a reconstruir. Las palabras emitidas por Gelber y por los demás entrevistados adquieren valor en la medida en que posibilitan a la cronista otorgar una dirección ordenadora a su relato; a partir de ello y de su observación rigurosa a la vez que situada, la narradora apunta a delimitar un sentido privado - aunque no íntimo - del personaje en el entorno de su cotidianeidad. Con ello, puede desmontar ciertos preconceptos identificados con el sentido público de Gelber. Frente a la idea de una vida atravesada por la sofisticación y el esnobismo, el relato propone la sencillez de un hogar privado de lujos, situado en una zona nada glamorosa de Capital Federal, el Barrio del Once. Frente a la identificación de Gelber como un músico internacional que se deleita con los viajes a sitios exclusivos, reivindica su sentimiento de pertenencia a la Argentina, su identificación como argentino. ${ }^{17} \mathrm{El}$ discurso desmiente a la vez la proposición de que Gelber sea un personaje antipático, reaccionario, o alejado de las cosas mundanas y populares. Resalta por el contrario su capacidad para adaptarse a diferentes entornos y su flexibilidad en el trato con los otros. Construye a la vez una imagen de seductor nato:

Ahí estaba: uno de los cien mejores pianistas del mundo con el extravagante aspecto de un conde de otra época - un fifí, un amanerado, un señorito - hablando del hambre y renegando, imprevisiblemente, de la idea de «lo distinguido» en un programa cuyos entrevistadores se alineaban con ideas populistas y quizás esperaban encontrar un pensamiento explícitamente reaccionario (107).

(...)

Para entonces, con su capacidad para reírse de sí mismo, rozar el tema de la sexualidad antes de que lo hicieran otros, mencionar la polio sin dramatismo y ejercer una crítica sobre su propio lugar de pertenencia, tenía al conductor y a los panelistas literalmente en el bolsillo (108).

Aquí, de manera semejante a lo examinado por nosotros respecto de otros perfiles de Guerriero, la construcción identitaria del «otro» puesta en relato por la cronista, funciona al mismo tiempo como posibilitadora de la puesta en objeto de la identidad propia. En Opus Gelber, el yo de la retratista asoma en diversos segmentos del texto, bien en su relación con el registro de lo cotidiano, bien para dar cuenta de su interacción con Gelber en la medida en que se siente interpelada por una figura que la inquieta y la fascina al mismo tiempo. En ese juego de seducción que vincula a la entrevistadora con su retratado, la primera acude a la autorreferencialidad toda vez que la actuación del personaje Gelber le plantea interrogantes acerca de sí misma, la incita a cuestionar/ se y la moviliza:

Asegura que, a veces, le da vergüenza porque mira la frente de alguien y ve pasar por allí «un cartel que indica que lo están pensando». La primera vez que dijo eso me toqué la frente, nerviosa, e intenté olvidarlo de inmediato (103).

En las conversaciones empieza a haber, siempre, un momento de regreso a fojas cero, como si jamás hubiéramos hablado, como si yo fuera una desconocida (202).

No le digo que, para concertar la cita, él miró la Laura Hidalgo Chica porque, de pronto, decir la «Laura Hidalgo Chica» en la cabina de un taxi y junto a un extraño adquiere un viso absurdo y pueril del que está completamente desprovisto dentro de las acolchadas paredes del departamento de Bruno. Cuando era chica, en casa de mi abuela paterna había un cuarto reservado para mis juegos al que llamábamos La Pieza de los Cachivaches. (...) Un día le dije a una chica nu eva en el barrio «Vamos a la Pieza de los Cachivaches», y me 
miró como si hubiera perdido el juicio. Desde entonces, jamás volví a utilizar ese nombre con desconocidos. Es la amenaza de esa posibilidad, la de exponer algo muy privado en público y recibir la súbita revelación de que suena ridículo, la que siento en el taxi. Entonces evito mencionar la Laura Hidalgo Chica, aun cuando sería el único argumento a mi favor (165).

Como su personaje perfilado, la cronista expone su subjetividad pero no se abre a la intimidad. El registro de lo íntimo está entonces ausente de la narración tanto en relación con la figura del músico como con la mirada acerca de sí que se erige en el texto, una mirada que es al mismo tiempo la mirada del «otro». Más allá de su condición de «verdad», apuntala sin embargo un relato construido desde la autenticidad, «en el sentido de promover un desnudamiento contrario a la prueba» (Gorodischer, 2018:19).

La «mirada» hacia ese «otro» posibilitará al mismo tiempo a la narradora construir el núcleo de sentido de lo que ella percibe como la experiencia vivencial de Gelber. Aquí, de manera semejante al perfil de Guerriero sobre la poeta Idea Vilariño, la soledad no constituye una condición fatal o un designio al que indefectible e inexorablemente la vida del músico se vea unida, sino una elección y a la vez, una condición necesaria para el trabajo artístico, labor posibilitadora de la situación de felicidad. Por ello, a lo largo de las páginas, reiterará los enunciados que sin explicitarlo, permiten sintetizar desde su subjetividad, la existencia de Gelber: «Un cuarto de hotel. Un hombre solo. Un piano./ Toda su vida ha sido eso» (183).

La soledad como condición existencial y al mismo tiempo como requerimiento para el trabajo creativo aparece también asociada a la figura de la escritora argentina Silvina Ocampo en La hermana menor, de Enriquez. El título del libro es ya revelador de al menos una de las direcciones que la cronista imprime a su historia: la argumentación en torno de la opacidad que la narradora en tanto escritora y personalidad de la cultura adquirió respecto de otras celebridades con las que compartió su vida. Como se conoce, Silvina fue la hermana de la influyente Victoria Ocampo, referente cultural en el campo intelectual argentino del siglo XX y fundadora y guía de la célebre revista Sur. Estuvo además casada con el escritor Adolfo Bioy Casares hasta el momento de su muerte, y su casa era frecuentada por otras figuras eximias de la literatura, tales como Jorge Luis Borges, amigo muy cercano de Bioy Casares. A medida que el relato avanza y a partir de la puesta en diálogo de los diferentes testimonios recogidos, asoma en la superficie textual un núcleo de sentido que sostiene la «identidad narrativa» (Arfuch, 2005, 2010) de Silvina Ocampo como la de una escritora a la sombra de la labor literaria de su hermana y de su esposo. Dicha construcción cobra fuerza hacia el final de la obra como afirmación concluyente:

Silvina Ocampo está enterrada en la bóveda familiar, que no tiene ninguna placa que lleve su nombre. Quien no sepa que su cuerpo está allí, no tendrá indicios para descubrirlo. Por fuera solo se ven placas con los nombres de Victoria y Angélica Ocampo, y las fechas del nacimiento y la muerte del padre.

No hay — todavía - nada que mencione a la hermana menor (Enriquez, 2018: 186).

La posición marginal y enigmática de Silvina Ocampo en el campo literario coetáneo a su producción ${ }^{18}$ se condice en el relato con la construcción de una figura de outsider en el entorno de su núcleo familiar. A partir tanto de los testimonios de quienes compartieron diferentes momentos de vida con Silvina como de las entrevistas que la cuentista ofreció en vida y de la bibliografía crítica sobre el período, la biógrafa retrata a esa personalidad indagando en los orígenes familiares y en los relatos de infancia. Establece asimismo una vinculación entre las historias plasmadas por Ocampo en sus cuentos y poemas, y las experiencias vitales de la escritora. La niñez adquiere una presencia insondable en ambos campos, en los que la cronista se zambulle para explorarlos con meticulosidad. El segmento que abre el libro titulado «Yo quiero que me quieran» alude a esa posición periférica de Silvina dentro de su familia: «(...) Silvina es la menor de seis hermanas, sus padres están cansados de criar hijas. Años más tarde, ella dirá que se sentía como "el etcétera de la familia"» (9). Advierte 
no obstante: «Ser el etcétera tiene sus ventajas. Su familia es de las más ricas y aristocráticas de la Argentina, y su padre, Manuel Ocampo, es un hombre riguroso y conservador. Pero los controles son más relajados con ella. Que, además, sabe esconderse. Silvina es secreta» (9).

Desde el inicio del retrato, la cronista despliega una mirada política - en diversos sentidos y direcciones - que signa u orienta de alguna manera su retrato sobre la personalidad misteriosa de la escritora. En primera instancia, lee las extravagancias de Silvina como productos de su posición de mujer con privilegios sociales y económicos. Es justamente desde este lugar que la Silvina niña expone un comportamiento irreverente al relacionarse con mendigos y personal de servicio que, según la propia protagonista anota en sus Invenciones del recuerdo, es producto de su fascinación por la pobreza; una fascinación que no se traduce en una toma de posición contra el orden social establecido, sino que se transforma en una especie de perversión que como actitud atraviesa la vida y la obra de Ocampo.

La mirada política que la cronista despliega en el texto se vincula también con la posición social de Silvina como mujer escritora frente a las «plumas masculinas» con las que intimaba y el menosprecio hacia su condición de narradora. Al respecto, la autora cita las palabras del crítico José Amícola, quien escribió:

El comentario de Borges sobre la crueldad sirve de documento para establecer qué poco había cambiado la consideración de la escritura de mujeres dentro de las empalizadas de la ciudad letrada hasta la segunda mitad del siglo XX. Borges parte de la suposición de que una joven de la alta burguesía no puede expresar nada que salga de los límites de la ternura y el amor... Pero el prefacio hace igualmente alusión a la divisoria de aguas entre sus propios relatos y los de Silvina, al acotar que los suyos se ciñen a lo esencial. Esta declaración permite leer entre líneas de qué modo también otro aspecto incómodo de los textos que comenta Borges concierne a la presunta incapacidad de esta autora para dar expresión a las sublimes esencias del género relato, según la tradición de las plumas masculinas (168).

La identidad narrativa ${ }^{19}$ construida en la biografía no es sin embargo uniforme. Los testimonios que la narradora incorpora en el libro no coinciden siempre y hasta resultan contradictorios en relación con ciertos aspectos de la personalidad de la escritora y de la posición que ella ocupa. En este sentido, el retrato no solo toma en cuenta las opiniones y miradas de amigos y familiares de Silvina, sino las declaraciones que la propia autora, extinta al momento del reportaje, dejó plasmadas en las entrevistas que concedió y en sus escrituras autobiográficas. Según ello, la posición marginal con la que se la identifica sería producto de una elección personal por parte de la escritora quien, como advierte la cronista, «nunca quiso ser el centro» (173). En la misma dirección, la narradora se aproxima a la relación de Silvina con Bioy Casares a partir del contraste entre versiones opuestas. Expone, por un lado, las interpretaciones como la del ama de casa del matrimonio, Jovita, quien en Los Bioy sostiene una «imagen de Silvina sufriente» (92) o la de Juanjo Hernández, quien en una entrevista con Guerriero da cuenta del destrato que a ojos del amigo de la pareja, Bioy proporcionaba a su mujer:

No les importaba el mundo exterior. (...) No sé si él respetaba el trabajo de su mujer. Cuando murió Silvina, y le dieron ese premio..., ese premio...El Cervantes...compartido, ¿no?...No sé.., bueno..., no importa, le preguntaron por Silvina. Y él suspiraba. Como si no pudiera soportar el dolor. Pero nunca tuvo una palabra de elogio, nunca dijo: "Mi mujer es una elocuente cuentista, una buena poeta" (91).

Otros testimonios, en cambio, dan cuenta de una forma diferente de relación entre ambos miembros del matrimonio. Cuestionan el lugar de víctima de la pareja con Bioy que se le asigna a Silvina. Para Ernesto Montequín, por ejemplo, cuyas palabras Enriquez cita en el texto, «la relación con Bioy fue muy compleja; ella tuvo una vida amorosa bastante plena. Ponerla en el lugar sufriente es una condescendencia hacia ella que no merece» ${ }^{[20]}(93)$. Esa complejidad es la que a 
ojos de la cronista, se reitera también en los tópicos de escritura de ficción de la escritora, quien recurrentemente trama historias donde los protagonistas son niños no solo marginales o subalternos, sino perversos.

La atención prestada por la retratista a la palabra de críticos y/o literatos que conocieron a Silvina de manera cercana toma relevancia en la medida en que posibilita ahondar en la obra creadora de la hermana menor de las Ocampo. En esa dirección, aquí, a diferencia de lo que ocurre con el retrato sobre Gelber de Guerriero, la cronista insiste a lo largo de las páginas en acercarse no solo a la experiencia vital de Silvina, sino y ante todo, a su escritura (sus cuentos, relatos autobiográficos, poesías). Y en este sentido, el gesto de reivindicar una obra que a primera vista fue ignota, o al menos, no reconocida por los congéneres de la escritora, es también un gesto político por parte de Enriquez. La decisión de retratar a una mujer que en vida se negaba a ser retratada ${ }^{[21]}$, que optaba por conservar un halo de misterio en torno de su intimidad y privacidad pues «no demostraba lo que le pasaba dentro», es la labor que acomete la biógrafa para perfilar de la manera más auténtica posible a ese personaje que se le presenta como atrayente a la vez que escurridizo. De manera semejante a lo delineado por Guerriero en su retrato sobre el célebre músico, el acceso a lo real será siempre a partir de la falta, de la imposibilidad de representación mimética. La verdad de la narración en ambos textos no se identificará, por lo tanto, con el alcance de una posible respuesta totalizadora, sino con la oportunidad para mostrar ese entramado como una búsqueda inacabable en pos de la construcción de sentidos susceptibles de otorgar posibles -y a la vez, inciertas- definiciones acerca de la vida de los personajes retratados.

\section{Referencias}

Amar Sánchez, Ana María (1992). El relato de los hechos. Rodolfo Walsh: testimonio y escritura. Beatriz Viterbo Editora.

Angulo Egea, María (s/f). Inmersiones. Crónica de viajes y periodismo encubierto. Colección Periodismo activo, 11. Universidad de Barcelona.

Arfuch, Leonor (2005). Problemáticas de la identidad. En Arfuch, Leonor (comp.). Identidades, sujetos, subjetividades (pp. 21-43). Prometeo Libros.

Arfuch, Leonor (2010). El espacio biográfico: dilemas de la subjetividad contemporánea. Fondo de Cultura Económica.

Bernabé, Mónica (2006). Prólogo. En Cristoff, María Sonia (comp.). Idea crónica. Literatura de no ficción Iberoamericana (pp. 7-25). Beatriz Viterbo Editora- Fundación TyPA.

Bernabé, Mónica (2010). Sobre márgenes, crónicas y mercancías. Boletín del Centro de Estudios de Teoría y Crítica Literaria, 15.

Bonano, Mariana (2014). Tendencias del periodismo narrativo actual. Las nuevas formas de contar historias en revistas y cronistas latinoamericanos de hoy. Question, 43.

Bonano, Mariana (2020a). Presentación al dossier Bonano, Mariana (coord.) La crónica latinoamericana actual y el periodismo narrativo del paso del siglo XX al XXI. Estudios de Teoría Literaria. Revista digital: artes, letras y humanidades, 9 (20), 3-10.

Bonano, Mariana (2020b). Escribir sobre mujeres. Perfiles y autofiguraciones en el periodismo narrativo de Leila Guerriero. En Maristany, José; Oliveto, Mariano; Pellegrino, Daniel y Redondo, Nilda (editores). Literaturas de la Argentina y sus fronteras: tensiones, disensos y convergencias, Actas del XX Congreso Nacional de Literaturas de la Argentina, Tomo 2 (pp. 417-424). José Maristany.

Carrión, Jorge (2012). Mejor que ficción. Crónicas ejemplares. Anagrama. 
Catelli, Nora (2007). En la era de la intimidad seguido de: El espacio autobiográfico. Beatriz Viterbo Editora.

Enriquez, Mariana (2018). La hermana menor. Un retrato de Silvina Ocampo. Anagrama.

Giordano, Alberto (1991). Modos del ensayo. Jorge Luis Borges-Oscar Masotta. Beatriz Viterbo.

González, Aníbal (1983). La Crónica Modernista Hispanoamericana. Ediciones José Porrúa Turanzas.

Gorodischer, Julián (2018). Prólogo. En Absatz, Cecilia et al., Los atrevidos. Crónicas íntimas de la Argentina (pp. 9-24). Marea.

Guerriero, Leila (2008). La lección de Homero. El Malpensante 88.

Guerriero, Leila (2009). Frutos extraños. Crónicas reunidas 2001-2008. Aguilar, Altea, Taurus, Alfaguara.

Guerriero, Leila (ed.) (2011). Los malditos. Ediciones Universidad Diego Portales.

Guerriero, Leila (2012). "Reportaje. La verdad y el estilo". El País, 18 de febrero. http://cultura.elpais.com/cultura/2012/02/15/actualidad/1329307 919_560267.html.

Guerriero, Leila (2019). Opus Gelber. Retrato de un pianista. Anagrama.

Ramos, Julio (1989). Desencuentros de la modernidad en América Latina. Literatura y política en el siglo XIX. Fondo de Cultura Económica.

Rotker, Susana (1992). La invención de la crónica. Letra Buena.

Walsh, Rodolfo (1998). Operación masacre. Planeta.

\section{Notas}

1. Hablamos del nicaragüense Rubén Darío (corresponsal de La Nación en 1898), del cubano José Martí (corresponsal en EEUU de La Nación y La Opinión Nacional, de México), del uruguayo José Enrique Rodó (corresponsal de la revista argentina $\mathrm{Ca}$ ras y Caretas), del mexicano Amado Nervo o del colombiano Luis Tejada Cano. Como expusimos en un trabajo previo (Bonano, 2020a), estos escritores ponen en vinculación elementos procedentes de la literatura y del periodismo, ya sea por el abandono de la exposición fáctica en pos de la interpretación de los datos y su contexto, o por la presencia de formas de hibridación entre técnicas ficticias y observación realista y detallada. Para el desarrollo de la crónica en América Latina y su relación con la no ficción, cfr. entre otros, Aníbal González (1983), Julio Ramos (1989), Susana Rotker (1992).

2. Las cursivas son del autor.

3. Si bien centramos nuestra atención en el desarrollo de la no ficción en Argentina a través de la figura de Walsh, podemos establecer que en América Latina resulta prominente también la obra del colombiano Gabriel García Márquez, quien hacia 1955 publica por entregas a El Espectador su célebre investigación Relato de un náufrago y, más tarde, hacia 1970, la edita en forma de libro como un relato de no ficción. Según postula Jorge Carrión (2012), cronista y autor de una antología de relatos de no ficción latinoamericanos, García Márquez y Walsh son los escritores latinoamericanos que otorgan a la crónica periodística la ambición y la estructura de la novela. Ellos, junto a otras figuras del siglo XX (Elena Poniatowska, Tomás Eloy Martínez, Carlos Monsiváis, Ryszard Kapuscinski, entre otros), representan al cronista contemporáneo que se aferra al poder de su mirada personal, reivindica la subjetividad, se esfuerza por hacer visibles a las minorías.

4. Entre la bibliografía dedicada al tema, Bernabé se ha referido puntualmente a las «crónicas de autor», entendiendo a estas como relatos en donde el autor es «alguien que se pone a sí mismo en observación», estableciendo «una relación, un lazo entre diferentes lecturas y voces, entre diferentes sitios y temporalidades» (2010: 9-10)

5. Sin la intención de circunscribir dicha práctica a ciertas figuras actuales, mencionamos aquí solo algunos nombres que a nuestro parecer resultan significativos dentro del panorama de la no ficción latinoamericana actual: Juan Villoro, Alberto Salcedo 
Ramos, Josefina Licitra, Leila Guerreiro, Gabriela Wiener, Cristian Alarcón, Martín Caparrós, María Moreno, Rodrigo Fresán, Pedro Lemebel, Juan Forn, entre otros.

6. Al respecto, es la propia Leila Guerriero, una de las autoras aquí estudiada, que define a las «historias de no ficción» como aquellas que «requieren largos trabajos de campo y que se narran utilizando recursos formales de la literatura de ficción» (2012). De acuerdo con lo señalado por la cronista, la propensión hacia este tipo de relatos por parte de la industria editorial, recoge un postulado que reitera una idea ya presente en la experiencia del Nuevo Periodismo sesentista: «la no ficción» produce, ahora, «formas y relatos más interesantes que la ficción» (Guerriero, 2012).

7. Las novelas son: Bajar es lo peor (1995), Cómo desaparecer completamente (2004), Este es el mar (2017), Nuestra parte de noche (2019). Esta última obtuvo el Premio Herralde de Novela en 2019. Las colecciones de cuentos se titulan Los peligros de fumar en la cama (2009) y Las cosas que perdimos en el fuego (2016).

[8]. Página/3o y Rolling Stone, de Argentina; Orsai (publicación hispano-argentina); El País y Vanity Fair, de España; El Malpensante y SoHo, de Colombia; Gatopardo y El Universal, de México; Etiqueta Negra, de Perú; Paula y El Mercurio, de Chile; Granta, del Reino Unido; Lettre Internationale, de Alemania y Rumanía; L'Internazionale, de Italia, entre otros. Respecto de los libros de no ficción, estos son Los suicidas del fin del mundo. Crónica de un pueblo patagónico (2005), Una historia sencilla (2013) y Opus Gelber. Retrato de un pianista (2018).

[9]. En el Prólogo a la antología de perfiles sobre autores hispanoamericanos titulada Los malditos, Guerriero establece: «Un perfil. Un perfil no es un ensayo ni una crítica ni un análisis literario. Un perfil es un perfil. Una mirada en primer plano sobre los trabajos y los días, los maridos y los hijos, los tíos y las bibliotecas, los armarios, los libros, los poemas, los viajes, los amantes, las manías, las píldoras, los electroshocks» (Guerriero, 2011:1). Como expusimos en un trabajo previo (Bonano, 2020b), la elección del perfil por parte de la autora sintoniza con aquello que ella demarca como central en su trabajo de escritura: la indagación en el «otro» instaura una mirada que es «la (...) de una persona que cuenta lo que ve o lo que, honestamente, cree ver» (Guerriero, 2009:392).

[10]. Todas las citas de La hermana menor corresponden a la edición de 2018, publicada por Anagrama en Barcelona, España, e impresa en Buenos Aires, Argentina.

[11]. De hecho, los perfiles conforman una porción significativa de la producción periodística de Guerriero. Al respecto, la construcción identitaria del «otro» asoma en los perfiles compilados por Guerreiro en Plano americano (2013), que contiene un total de 21 perfiles publicados originalmente en suplementos culturales de medios nacionales e internacionales, o en revistas culturales de circulación digital. Por otra parte, el volumen de su autoría titulado Frutos extraños (2009) recoge en una de sus secciones varios perfiles publicados antes en medios.

[12]. Nora Catelli (2007) señala el carácter doble, etimológicamente separado pero semánticamente ambiguo del término «intimidad»: «Lo íntimo es aquello más interior que define la zona espiritual reservada de una persona o grupo y posee dos acepciones. La primera, introducirse un cuerpo por los poros o espacios huecos de una cosa. La segunda, introducirse en el afecto o ánimo de uno, estrechar una amistad» (46). «(...) lo íntimo tiene que ver con dos actitudes distintas del sujeto o sobre el sujeto, dos maneras de la intervención en el ánimo o en el cuerpo propio o de otro. Gestos vinculados con la penetración (física pero figuradamente también moral o psicológica) de un sujeto sobre sí mismo o sobre otro, y con la introducción (física pero figuradamente también psíquica y moral) de algo en un sujeto; o de un sujeto a otro (en el sentido de presentación). Los dos términos denotan movimiento; todos ellos remiten a impulsos físicos y de la voluntad. Pero, además, muestran que la noción de lo subjetivo está marcada por la incorporación o interiorización de otro sujeto u otra cosa» (46).

[13]. Se aclara que los espacios en blanco presentes entre las frases pertenecen al original. Todas las citas de la obra de Guerriero son extractadas de la edición de 2019 publicada por Anagrama.

[14]. Otro momento del texto referido a esta no apertura a la intimidad que manifiesta el personaje, es cuando la narradora expone el uso del lenguaje en doble sentido por parte de Gelber en tanto estrategia para obstaculizar el acceso a cualquier aspecto de esa zona identificada con lo íntimo: «Si se le pregunta por las partes arduas de una vida nómade dice: "Los trenes no llegan a tiempo, perdés la conexión de los aviones, en los hoteles te hacen ruido", o cuenta la anécdota del inesperado concierto de Rachmáninov que tuvo que dar en Palermo, Sicilia, y la anécdota de la huelga de trabajadores de un teatro que le impidió tocar en Catania. Si se le insiste - ¿y la soledad, y el vértigo, y la vida en una maleta? - dice, enervado: «No. Vos estás buscando momentos psicológicos difíciles. Pero no hay. Hay cosas que no podés cambiar. La Tierra es redonda y tenés jet lag. (...) No hay mucho más"» 
(166). La imposibilidad de penetrar en esa intimidad es experimentada por el sujeto narrativo como un fracaso: «Varias veces me preguntará: "¿Qué pensás de mí ahora que me conocés?". Una, de tantas, le diré: "Que solo vos sabés quién sos". Lo cual es una declaración de fracaso» (83).

[15]. En su texto sobre el célebre mago argentino de una sola mano, René Lavand, creador de una técnica de ilusionismo con naipes llamada lentidigitación, Guerriero (2009) afirma que el perfil no es otra cosa que «la mirada del otro» (392), una mirada que no es siempre - casi nunca - la misma y que como todo ilusionismo, instaura una «mentira» - honesta - : la «bella y sutil mentira del arte» (261).

[16]. La relación entre crónica íntima y los aspectos arriba señalados son abordados por Julián Gorodischer (2018), entre otros. En relación con Gelber, la referencia al cuerpo es fundamental en la medida en que la enfermedad que lo afecta, la poliomielitis, a los seis años, así como las marcas que la misma deja en su físico, condiciona de alguna manera el estilo de vida del músico, quien declara que no le gusta estar solo. Tiene conciencia de su fragilidad corporal y por ello, necesita compañía. Digamos que para el personaje que Gelber construye acerca de sí, prima el utilitarismo antes que el gusto en la elección de su acompañante: «A veces no es la persona, sino el servicio que me da esa persona. Si me quedo solo una noche, me queda una sensación de impotencia debido a mi estado físico. No me gusta estar solo. Porque siempre he tenido conciencia de necesitar ayuda. Estar solo no es mi cup of tea. Siempre estuve atendido» (97).

[18]. Uno de los tantos segmentos del libro en los que asoma esta posición de Silvina en el campo literario es, por ejemplo, cuando la biógrafa se refiere a la relación de la escritora con el grupo Sur: «A Silvina Ocampo se la suele incluir en el "Grupo Sur" porque desde ahí, desde la revista de su hermana y luego desde la editorial Sur, dio a conocer su literatura. Pero Sur no era solo una revista de literatura: era una tribuna de disputa cultural. Y en ese sentido el lugar dentro de la revista de Silvina, en relación con los debates estéticos y políticos que allí se jugaban, no era central sino más bien, y quizá intencionalmente, secundario. Periférico» (42).

[19]. Para la noción de identidad narrativa, remitimos a la delimitación realizada por nosotros en el trabajo ya citado (Bonano, 2020b). Señalábamos allí que dicha categoría es conceptualizada por Leonor Arfuch $(2005,2010)$ en relación con los géneros biográficos y los dilemas de la subjetividad contemporánea, a partir del filósofo y pensador Paul Ricoeur. La autora la concibe en términos no de una positividad esencialista, sino desde una dimensión conflictiva; plantea al respecto que se trata de «una posicionalidad relacional, confluencia de discursos donde se actualizan diversas posiciones de sujeto no susceptibles de ser fijadas más que temporalmente ni reductibles a unos pocos significados "claves"» (2005: 31).

[20]. Al respecto, en varios segmentos del libro se alude a la posible bisexualidad de Silvina y a sus eventuales amantes como la escritora Alejandra Pizarnik o Edgardo Cozarinsky. La relación matrimonial al parecer también estuvo atravesada por la presencia de una amante compartida entre Silvina y Bioy.

[21]. «No le gustaba que la fotografiasen, y sin embargo hay muchas fotos suyas» (72). Una vez más, aparece en la biografía la complejidad de la personalidad de la escritora. La aparente reticencia a las fotos que la narradora expone a partir de los testimonios de los amigos de Silvina, se relaciona con la percepción de la escritora acerca de sí como «fea». No obstante, todos concuerdan en afirmar que Silvina tenía una belleza no convencional y ejercía un juego de seducción cuando posaba frente a sus interlocutores o espectadores eventuales. 